\title{
AVALIAÇÃO DA DEVOLUÇÃO DE SERAPILHEIRA EM UMA FLORESTA ESTACIONAL DECIDUAL EM ITAARA, RS, BRASIL ${ }^{1}$
}

\author{
ESTIMATE OF LITTER FALL IN SEASONAL DECIDUOUS FOREST IN ITAARA, RS, BRAZIL
}

\author{
Hamilton Luiz Munari Vogel ${ }^{2} \quad$ Mauro Valdir Schumacher $^{3} \quad$ Peter Trüby $^{4} \quad$ Elisabete Vuaden $^{5}$ \\ RESUMO
}

O presente trabalho foi realizado na fazenda da Brigada Militar no município de Itaara, RS, Brasil, e teve como principal objetivo avaliar a devolução de serapilheira em uma Floresta Estacional Decidual. Para a coleta de serapilheira, foram demarcadas seis parcelas de $25 \mathrm{~m} \mathrm{x} 17 \mathrm{~m}$ cada, alocadas no interior da floresta. Em cada parcela, foram distribuídos cinco coletores, totalizando 30 coletores, constituídos por uma moldura de ferro de forma circular, com $50 \mathrm{~cm}$ de diâmetro. As coletas de serapilheira foram realizadas mensalmente, durante um período de 2 anos. No laboratório, o material foi separado nas frações folhas, galhos finos $(<1$ cm) e miscelânea (flores, frutos, sementes e restos vegetais não-identificáveis). Nos dois anos de coleta, houve grande devolução de serapilheira no início do inverno e principalmente na primavera, aumentando nos meses de setembro e novembro, no primeiro ano. No segundo ano, apesar da menor devolução mensal, essa tendência manteve-se mais ou menos constante, indicando um padrão sazonal nessa floresta. A devolução média anual de serapilheira foi de $7436,0 \mathrm{~kg} \mathrm{ha}^{-1}$, com uma distribuição relativa de 71,7\% de folhas, 16,5\% de galhos finos e 11,8\% de miscelânea. Não foi verificada uma correlação significativa entre as variáveis climáticas precipitação e temperatura e a devolução de serapilheira.

Palavras-chave: nutrição; folhas; floresta nativa.

\section{ABSTRACT}

This work was carried out in the farm of the Military Brigade in the city of Itaara, RS, Brazil. The present work has as main objective to evaluate the estimate of litter fall in Seasonal Deciduous Forest. For the litter collection, six plots of $25 \mathrm{~m} \mathrm{x} 17 \mathrm{~m}$ had been demarcated, placed in the forest. In each plot, five litter traps had been distributed, totalizing 30 traps. The litter collections had been carried out monthly, during a period of 2 years (December of 2002 to November of 2004). In the laboratory, the material was separated in fractions, leaves, small twigs and miscellaneous (flowers, fruits, seeds and residues not identified). During the two years of collection, it could be observed great litter deposition in the in the beginning of the winter and mainly in the spring with the biggest depositions during September and November, indicating a standard seasonal in this forest. The leaves had been responsible for $71.3 \%$ of the composition of the litter, the fine twigs had contributed with $16.7 \%$, and the miscellany with the lesser ratio of $12.1 \%$, in the two years of collection. A significant correlation between the litter deposition and the climatic variables was not verified.

Keywords: nutrition; biomass; native forest.

\section{INTRODUÇÃO}

No Brasil, os estudos envolvendo os ecossistemas naturais, com ênfase na ciclagem de nutrientes em florestas nativas, surgem da necessidade de se ampliar e aprofundar os conhecimentos sobre os aspectos nutricionais em plantações florestais com espécies nativas, tendo em vista sua utilização nas atividades aplicadas à implantação de maciços puros ou mistos destinados à recuperação de áreas degradadas ou mesmo o cultivo de essências nativas para produção de madeiras de lei (POGGIANI e SCHUMACHER, 2000).

1. Parte da Tese de doutorado do primeiro autor.

2. Engenheiro Florestal, Dr., Professor da Universidade Estadual do Rio Grande do Sul, Rua Pinheiro Machado, 2858, Aparamento 201, Bairro Centro, CEP 97050-000, Santa Maria (RS). hamiltonvogel@yahoo.com.br

3. Engenheiro Florestal, Dr., Professor Associado do Departamento de Ciências Florestais, Centro de Ciências Rurais, Universidade Federal de Santa Maria, Campus Universitário, CEP 97105-900, Santa Maria (RS). Bolsista do CNPq. schuma@ccr.ufsm.br

4. Engenheiro Florestal, Dr., Professor da Albert-Ludwigs-Universität Freiburg, Bertoldstr, 17, 79085, Freiburg, Alemanha. peter.trueby@bodenkunde.uni-freiburg.de

5. Engenheira Florestal, Mestranda do Programa de Pós-Graduação em Engenharia Florestal, Centro de Ciências Rurais, Universidade Federal de Santa Maria, Campus Universitário, CEP 97105-900, Santa Maria (RS). Bolsista da CAPES. elisabetevuaden@yahoo.com.br

Recebido para publicação em 9/11/2005 e aceito em 7/05/2007. 
O estudo da ciclagem de nutrientes (ciclo biogeoquímico) desempenha um papel importante no conhecimento das condições e dinâmica dos processos internos dos ecossistemas naturais, que auxiliam no entendimento das rápidas mudanças provocadas pela exploração florestal no meio ambiente (FEGER e RASPE, 1998).

A ciclagem biogeoquímica (solo-planta-solo) de nutrientes, bastante pronunciada em povoamentos florestais após o fechamento de copas, tem efeitos estimulantes sobre o crescimento das raízes finas na superfície do solo, devido ao provimento de um microambiente propício ao seu desenvolvimento e por ser uma fonte rica de nutrientes (GONÇALVES e MELLO, 2000).

Reissmann e Wisnewski (2000) ressaltam que a absorção de nutrientes diretamente da serapilheira representa um fluxo importante para atender à demanda nutricional das árvores. O tipo de vegetação e as condições ambientais são os fatores que mais influem na quantidade e qualidade do material que cai no solo (MOREIRA e SIQUEIRA, 2002).

De acordo com Poggiani e Schumacher (2000), a quantia de material orgânico, depositado ao longo de um ano, em florestas, está relacionada principalmente com as condições climáticas, sendo menor nas regiões frias e maior nas regiões equatoriais quentes e úmidas.

A quantidade de material vegetal que cai do dossel formando a serapilheira em Florestas Estacionais, no Sul do Brasil, atinge várias toneladas por hectare, conforme diversos trabalhos já realizados (CUNHA, 1997; BARICHELLO et al., 2000; KÖNIG et al., 2002; VOGEL et al., 2003; BRUN, 2004).

A quantidade de material orgânico depositado ao longo de um ano está relacionada principalmente com as condições climáticas, sendo menor nas regiões frias e maior nas regiões equatoriais quentes e úmidas. Por exemplo, florestas situadas em regiões árticas ou alpinas produzem anualmente cerca de uma tonelada de serapilheira por hectare; florestas temperadas frias, 3,5 toneladas; florestas temperadas quentes, 5,5 toneladas; e florestas equatoriais, cerca de 11 toneladas (BRAY e GORHAM, 1964).

Assim, a serapilheira, em um ecossistema florestal, é responsável pela retenção de grandes quantidades de nutrientes, sendo uma fonte importante de devolução de nutrientes para o solo (ANDRAE e KRAPFENBAUER, 1983; REIS e BARROS, 1990; BRUN et al., 1999; ALBERTI et al., 2000; SCHUMACHER et al., 2002; TOLEDO et al., 2002; VOGEL et al., 2003; CALDEIRA, 2003; BRUN, 2004), constituindo uma via importante do ciclo biogeoquímico, especialmente em solos altamente intemperizados, nos quais a biomassa vegetal é o principal reservatório de nutrientes (REIS e BARROS, 1990).

Neste contexto, o trabalho teve como principal objetivo avaliar a devolução de serapilheira, ao longo de dois anos, em uma Floresta Estacional Decidual, em Itaara, RS, Brasil.

\section{METODOLOGIA}

\section{Caracterização da área de estudo}

\section{Área experimental}

O trabalho foi realizado em uma fazenda pertencente à Brigada Militar (CETRAPA - Centro de Estudos e Treinamento, Reprodução Animal e Proteção Ambiental), no município de Itaara, Rio Grande do Sul, Brasil. O município de Itaara está localizado na Serra de São Martinho, na região fisiográfica do Planalto Médio. Verifica-se, na Figura 1, a localização do município de Itaara e da área experimental com as coordenadas médias, no Estado do Rio Grande do Sul. A altitude média do local é de $400 \mathrm{~m}$. 


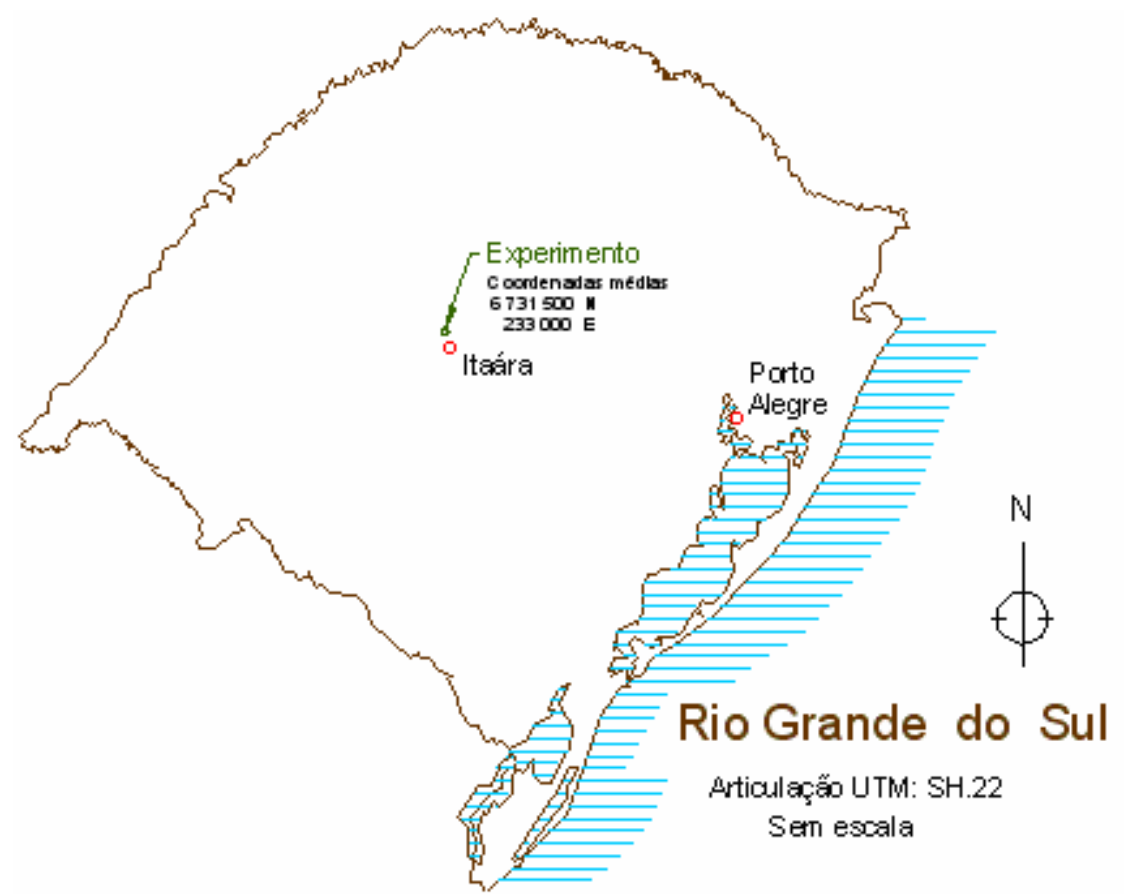

FIGURA 1: Localização do município de Itaara e da área experimental no Estado do Rio Grande do Sul, Brasil.

FIGURE 1: Localization of the city of Itaara and the experimental area in the state of Rio Grande do Sul, Brazil.

\section{Clima}

A região em que o município de Itaara está inserido apresenta a variedade climática Cfa (segundo a classificação climática de Köppen), caracterizada pela ocorrência de chuvas durante todos os meses do ano, possuindo a temperatura média do mês mais quente superior a $22^{\circ} \mathrm{C}$ e a do mês mais frio entre 18 e $-3^{\circ} \mathrm{C}$, com precipitações variando entre 1700 e 1800 milímetros anuais (MORENO, 1961).

Solo

O solo da região é caracterizado como Neosolo Litólico eutrófico típico (STRECK et al., 2002). Essa classe de solos é descrita pela EMBRAPA (1999) como "solos com horizonte A ou O hístico com menos de $40 \mathrm{~cm}$ de espessura, assente diretamente sobre a rocha ou sobre um horizonte $\mathrm{C}$ ou $\mathrm{Cr}$ ou sobre material com 90\% ou mais de sua massa, constituída por fragmentos de rocha com diâmetro maior que 2 mm (cascalhos, calhaus e matacões)." O solo do local do estudo é bastante raso, ficando em torno de $35 \mathrm{~cm}$ de profundidade.

\section{Vegetação arbórea}

De acordo com o inventário realizado na floresta do estudo antes da coleta da biomassa por Longhi et al. (2005), foram encontradas com maior freqüência as espécies arbóreas: Allophylus edulis (A. St.-Hil. et al.) Radlk, Caliandra tweediei Benth., Cupania vernalis Cambess., Dalbergia frutescens (Vell.) Britton, Eugenia hyemalis Cambess., Helietta apiculata Benth., Lithraea brasiliensis Marchand, Lithraea molleoides (Vell.) Engl., Luhea divaricata Mart. et Zucc., Matayba eleagnoides Radlk., Nectandra megapotamica (Spreng.) Mez, Ocotea puberula (A. Rich.) Ness, Ocotea pulchella Mart., Parapiptadenia rigida (Benth.) Brenan, Patagonula americana L., Quillaja brasiliensis (A. St.-Hill. et Tul.) Mart., Sebastiana brasiliensis Spreng. e Sebastiania commersoniana (Baill.) L. B. Sm. et Downs, entre outras.

Conforme Greff et al. (2006), as principais famílias da comunidade encontradas foram Leguminosae, Euphorbiaceae e Sapindaceae, devido aos seus representantes possuírem os maiores valores no Ìndice de Valor de Importância. A família com maior número de representantes foi Myrtaceae, sendo todos eles com baixos valores nos índices relativos; a diversidade da floresta é semelhante a outras da região, não sendo maior, pelo longo período de exploração sofrida. No local, há indícios de que, no passado, a área já tenha sido explorada (cepas queimadas e cepas ramificadas). 
Conforme as informações da Brigada Militar, responsável pela floresta do estudo, estima-se que a mesma tenha em torno de 70 anos de idade, e, de acordo com as descrições de Longhi et al. (2005) e Greff et al. (2006), pressupõe-se que a floresta esteja em estágio secundário de sucessão.

\section{Amostragem}

\section{Serapilheira depositada}

Para a coleta de serapilheira depositada, foram demarcadas seis parcelas de $25 \mathrm{~m} \mathrm{x} 17 \mathrm{~m}$ cada, alocadas no interior da floresta. Em cada parcela, foram distribuídos cinco coletores, totalizando assim 30 coletores. Estes foram constituídos de uma moldura de ferro de forma circular, com $50 \mathrm{~cm}$ de diâmetro, fixados no local, com uma altura de um metro a partir do solo (Figura 2). Em cada coletor, prendeu-se uma tela de sombrite $(2 \mathrm{~mm}) \mathrm{com} 50 \mathrm{~cm}$ de comprimento.

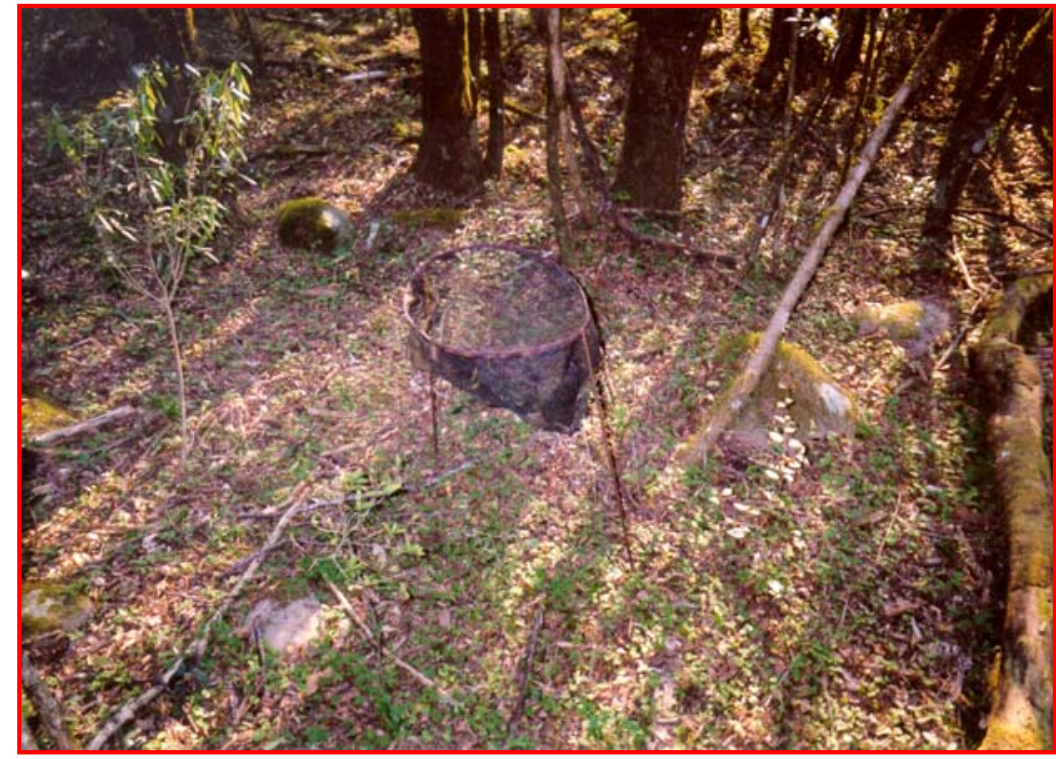

FIGURA 2: Aspecto de um dos coletores de serapilheira utilizado. Itaara, RS, Brasil.

FIGURE 2: Aspect of one of the used litter traps.

As coletas de serapilheira foram realizadas mensalmente, durante um período de 2 anos (de dezembro de 2002 a novembro de 2004). O material coletado foi devidamente identificado, acondicionado e levado até o Laboratório de Ecologia Florestal, do Departamento de Ciências Florestais da Universidade Federal de Santa Maria (UFSM), onde foi separado nas frações, folhas, galhos finos $(<1 \mathrm{~cm})$ e miscelânea (flores, frutos, sementes e restos vegetais não-identificáveis). Após a separação, o material foi colocado em estufa a $75^{\circ} \mathrm{C}$ até atingir peso constante. Na seqüência, o material foi moído em moinho do tipo Willey e pesado com balança digital de 0,01 g de precisão, obtendo-se assim o peso seco de cada fração.

\section{RESULTADOS E DISCUSSÃO}

\section{Serapilheira}

\section{Produção de serapilheira}

Na Tabela 1, pode-se verificar a deposição total de serapilheira e seus componentes nos dois anos de coleta. Ao longo desse período, a deposição total de serapilheira foi de $14871,9 \mathrm{~kg} \mathrm{ha}^{-1}$,com uma média anual de 7436,0 $\mathrm{kg} \mathrm{ha}^{-1}$ depositados sobre o solo.

Observa-se, na Tabela 1, que, no segundo ano de coleta, a deposição de serapilheira foi menor do que no primeiro ano. Já a deposição de galhos finos e miscelânea manteve-se mais ou menos constante nos dois anos de observação. Possivelmente estas diferenças podem estar relacionadas a vários fatores, como as condições climáticas da região e as características fenológicas das árvores. 
TABELA 1: Serapilheira depositada ao longo dos dois anos de estudo na Floresta Estacional Decidual em Itaara, RS, Brasil.

TABLE 1: Litter fall during a period of 2 years in Seasonal Deciduous Forest in Itaara, RS, Brazil.

\begin{tabular}{|c|c|c|c|c|}
\hline \multirow{2}{*}{ Variáveis } & \multicolumn{4}{|c|}{ Ano $2003\left(\mathrm{~kg} \mathrm{ha}^{-1} \mathrm{ano}^{-1}\right)$} \\
\hline & Folhas & Galhos finos & Miscelânea & Serapilheira $^{1}$ \\
\hline Total & 6252,4 & 1283,2 & 871,0 & 8406,6 \\
\hline Média mensal & 521,0 & 106,9 & 72,6 & 700,5 \\
\hline Desvio & 186,7 & 71,5 & 57,6 & 246,4 \\
\hline CV (\%) & 35,8 & 66,8 & 79,3 & 35,2 \\
\hline$(\%)$ & 74,4 & 15,3 & 10,4 & 100 \\
\hline \multirow{2}{*}{ Variáveis } & \multicolumn{4}{|c|}{ Ano $2004\left(\mathrm{~kg} \mathrm{ha}^{-1} \mathrm{ano}^{-1}\right)$} \\
\hline & Folhas & Galhos finos & Miscelânea & Serapilheira $^{1}$ \\
\hline Total & 4410,7 & 1165,6 & 889,1 & 6465,3 \\
\hline Média mensal & 367,6 & 97,1 & 74,1 & 538,8 \\
\hline Desvio & 126,3 & 81,3 & 48,4 & 155,2 \\
\hline CV (\%) & 34,4 & 83,7 & 65,3 & 28,8 \\
\hline$(\%)$ & 68,2 & 18,0 & 13,8 & 100 \\
\hline \multirow{2}{*}{ Variáveis } & \multicolumn{4}{|c|}{ Média anual $\left(\mathrm{kg} \mathrm{ha}^{-1}\right)$} \\
\hline & Folhas & Galhos finos & Miscelânea & Serapilheira $^{1}$ \\
\hline Média anual & 5331,5 & 1224,4 & 880,1 & 7436,0 \\
\hline (\%) & 71,7 & 16,5 & 11,8 & 100 \\
\hline
\end{tabular}

Em que: 1 = Serapilheira (soma das folhas + galhos finos + miscelânea).

Nota-se, na Tabela 1, que a média anual da distribuição relativa da serapilheira foi de: folhas com 71,7\%, galhos finos com 16,5\% e miscelânea com 11,8\%. A deposição média anual de folhas, nesse trabalho, esteve dentro do intervalo observado na literatura para Florestas Estacionais no Sul do Brasil, conforme os dados de alguns trabalhos citados a seguir.

König et al. (2002) encontraram em uma Floresta Estacional Decidual secundária, próxima ao município de Santa Maria, RS, uma deposição anual de serapilheira de 9,2 $\mathrm{Mg}_{\text {ha }}{ }^{-1}$, sendo composta de 67,8\% de folhas, $19,3 \%$ de galhos finos e 12,9\% de miscelânea.

Já Cunha (1997), na região de Vale Vêneto, RS (Floresta Estacional Decidual), constatou uma deposição média anual de serapilheira na capoeira (com 13 anos de idade) de 5,8 $\mathrm{Mg} \mathrm{ha}^{-1}$ com 73\% de folhas; no capoeirão (19 anos), de $8,0 \mathrm{Mg} \mathrm{ha}^{-1}$ com 65\% de folhas; e, na floresta secundária (mais de 30 anos), de 9,5 $\mathrm{Mg} \mathrm{ha}^{-1}$ com 65\% de folhedo.

Brun et al. (1999), em três estágios sucessionais (Capoeirão, Floresta Secundária e Floresta Clímax), em uma Floresta Estacional Decidual, no município de Santa Tereza-RS, registraram uma queda de serapilheira, no primeiro ano de estudo, de 9,7 $\mathrm{Mg} \mathrm{ha}^{-1}$ na Floresta Clímax, e, na Floresta Secundária e no Capoeirão, de 7,4 e 6,6 Mg ha ${ }^{-1}$, respectivamente. Na Floresta Clímax, a fração folhas representou 65,6\% do total da serapilheira coletada, enquanto que, na floresta secundária e no capoeirão, esta fração representou $69,7 \%$ e 70,8\% respectivamente.

Em uma revisão de âmbito mundial, Bray e Gorham (1964) concluíram que, nas diferentes zonas macroecológicas, de um modo geral, as serapilheiras amostradas em diferentes florestas do mundo são compostas de 60 a $80 \%$ por folhas, de 1 a $15 \%$ por frutos, de 12 a $15 \%$ por ramos e de 1 a $25 \%$ por cascas de árvores.

Quanto à variabilidade das frações, pode-se verificar altos valores do coeficiente de variação, principalmente para as frações galhos finos e miscelânea. Talvez para as frações galhos finos seja necessário um número maior de coletores, ou uma área maior de coleta por coletor. Essa alta variabilidade para os galhos finos também foi observada por Figueiredo Filho et al. (2003), que achou um coeficiente de variação de $110 \%$.

Também com relação à fração miscelânea, a alta variação pode estar associada à derrubada de detritos diversos, como por exemplo fragmentos de casca, uma vez que no local dos coletores ocorre bastante 
derrubada de árvores mortas e galhos grossos, típico de uma floresta que encontra-se em sucessão. Outro fato importante é o período de floração de algumas espécies, pois notou-se, em alguns meses de coleta, grande incidência de pequenas flores brancas e sementes em abundância, aumentando a quantidade da fração miscelânea nestes meses, e, conseqüentemente, o respectivo coeficiente de variação.

\section{Sazonalidade da serapilheira} de coleta.

Na Figura 3, é possível observar a sazonalidade da deposição de serapilheira ao longo dos dois anos

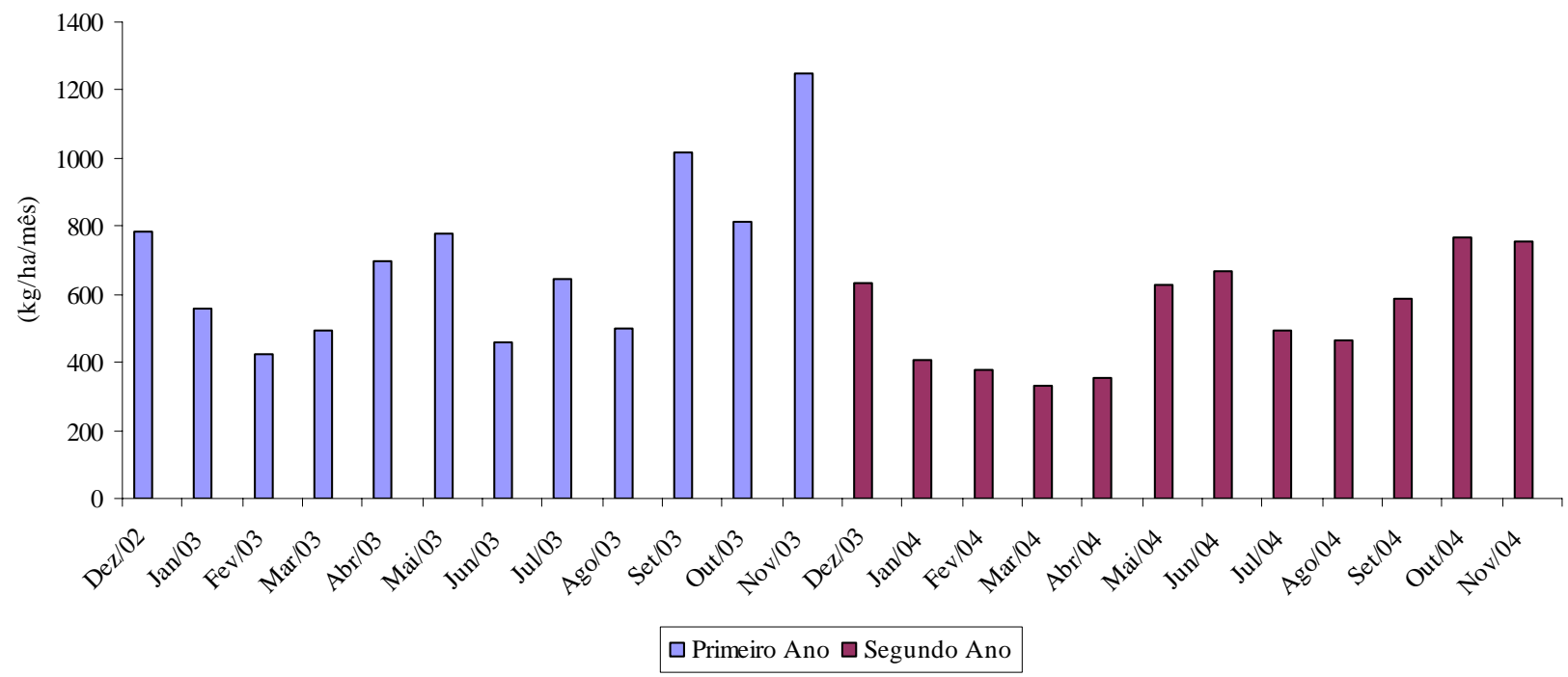

FIGURA 3: Sazonalidade da serapilheira ao longo dos dois anos de coleta na Floresta Estacional Decidual em Itaara, RS, Brasil.

FIGURE 3: Litter seasonality during a period of 2 years in Seasonal Deciduous Forest in Itaara, RS, Brazil.

Observa-se, na Figura 3, que, no primeiro ano de coleta, houve grande deposição de serapilheira no início do inverno e principalmente na primavera, com pico de deposição no mês de novembro. No segundo ano, apesar da menor deposição mensal, essa tendência manteve-se mais ou menos constante, indicando um padrão sazonal de deposição de serapilheira nessa floresta.

Uma maior deposição de serapilheira na primavera também foi observado por Fegueiredo Filho et al. (2003), em uma Floresta Ombrófica Mista, no sul do Paraná.

Brun et al. (1999), em três estágios sucessionais, em uma Floresta Estacional Decidual, no município de Santa Tereza, observaram que as maiores quedas de serapilheira ocorreram na primavera e verão, entre os meses de novembro e fevereiro, e as menores, no outono e inverno, entre os meses de abril e agosto.

Em estudo realizado por König et al. (2002), também em Floresta Estacional Decidual, próxima ao município de Santa Maria, RS, os autores verificaram que os maiores picos de deposição da serapilheira ocorreram entre os meses de julho e setembro, com maior queda de folhas em setembro, quando se inicia o período de elevação da temperatura. Os autores ressaltam ainda que tal estratégia é característica das Florestas Estacionais Deciduais do sul do Brasil, nas quais uma estagnação do crescimento provocada pelo inverno faz com que ocorra a eliminação da folhagem senescente, visando o novo período de crescimento, que se inicia com a primavera, com o aparecimento de nova folhagem.

Cunha (1997) observou que os meses de maior derrubada de serapilheira foram outubro e maio, na floresta Estacional Decidual da região de Vale Vêneto, RS. De acordo com esse autor, a maioria das espécies encontradas na Floresta Estacional do sul do Brasil, é originária de regiões com estação seca bem definida, como o interior da região Sudeste e a parte oriental da região Centro-Oeste. Nestas regiões, o final da estação seca coincide com o final do inverno na região Sul. Portanto, fatores genéticos também têm influência marcante sobre a zasonalidade na produção de serapilheira na Floresta Estacional Decidual no Rio Grande do Sul. 
Como a sazonalidade da serapilheira pode estar relacionada com as variáveis climáticas, esta foi correlacionada com a temperatura média mensal e a precipitação mensal (Tabela 2). Os dados meteorológicos (temperatura média mensal e precipitação mensal) usados no estudo foram obtidos da Plataforma de Coleta de Dados do INPE de São Martinho da Serra, RS, por ser a estação mais próxima do local do estudo.

Os resultados da Tabela 2 demonstram que não há correlação significativa entre as frações folhas, galhos finos e serapilheira com a temperatura média e a precipitação mensal, sendo somente significativo para a fração miscelânea, com a temperatura média a 1\% de probabilidade de erro.

König et al. (2002), em Floresta Estacional Decidual próxima ao município de Santa Maria, RS, verificaram que a deposição de serapilheira apresentou correlações negativas com a temperatura, não sendo significativa com a precipitação. Já Figueiredo Filho et al. (2003) obtiveram baixa correlação linear com a precipitação $(r=0,36)$ e com a temperatura $(r=-0,10)$, em uma Floresta Ombrófica Mista no sul do Paraná.

TABELA 2: Coeficientes de correlação de Pearson, entre os componentes da serapilheira da Floresta Estacional Decidual e as variáveis climáticas, em Itaara, RS, Brasil.

TABLE 2: Pearson coefficients correlation between the litter components in Seasonal Deciduous Forest and the climate variables in Itaara, RS, Brazil.

\begin{tabular}{c|ccccc}
\hline Variável climática & Folhas & Galhos finos & Miscelânea & Serapilheira $^{1}$ \\
\hline Temperatura $\left({ }^{\circ} \mathrm{C}\right)$ & $-0,26^{\mathrm{ns}}$ & $-0,20^{\mathrm{ns}}$ & $0,46^{* *}$ & $-0,19^{\mathrm{ns}}$ \\
Precipitação $(\mathrm{mm})$ & $0,16^{\mathrm{ns}}$ & $0,21^{\mathrm{ns}}$ & $0,07^{\mathrm{ns}}$ & $0,22^{\mathrm{ns}}$ \\
\hline
\end{tabular}

Em que: 1 = Serapilheira (soma das folhas + galhos finos + miscelânea); ns = não-significativo a 1\% de probabilidade de erro; ** = significativo a 1\% de probabilidade de erro. Fonte: INPE/São Martinho da Serra, RS.

Assim, nas Figuras 4 e 5, estão apresentadas a sazonalidade da deposição da serapilheira com a temperatura média mensal e a precipitação mensal, respectivamente.

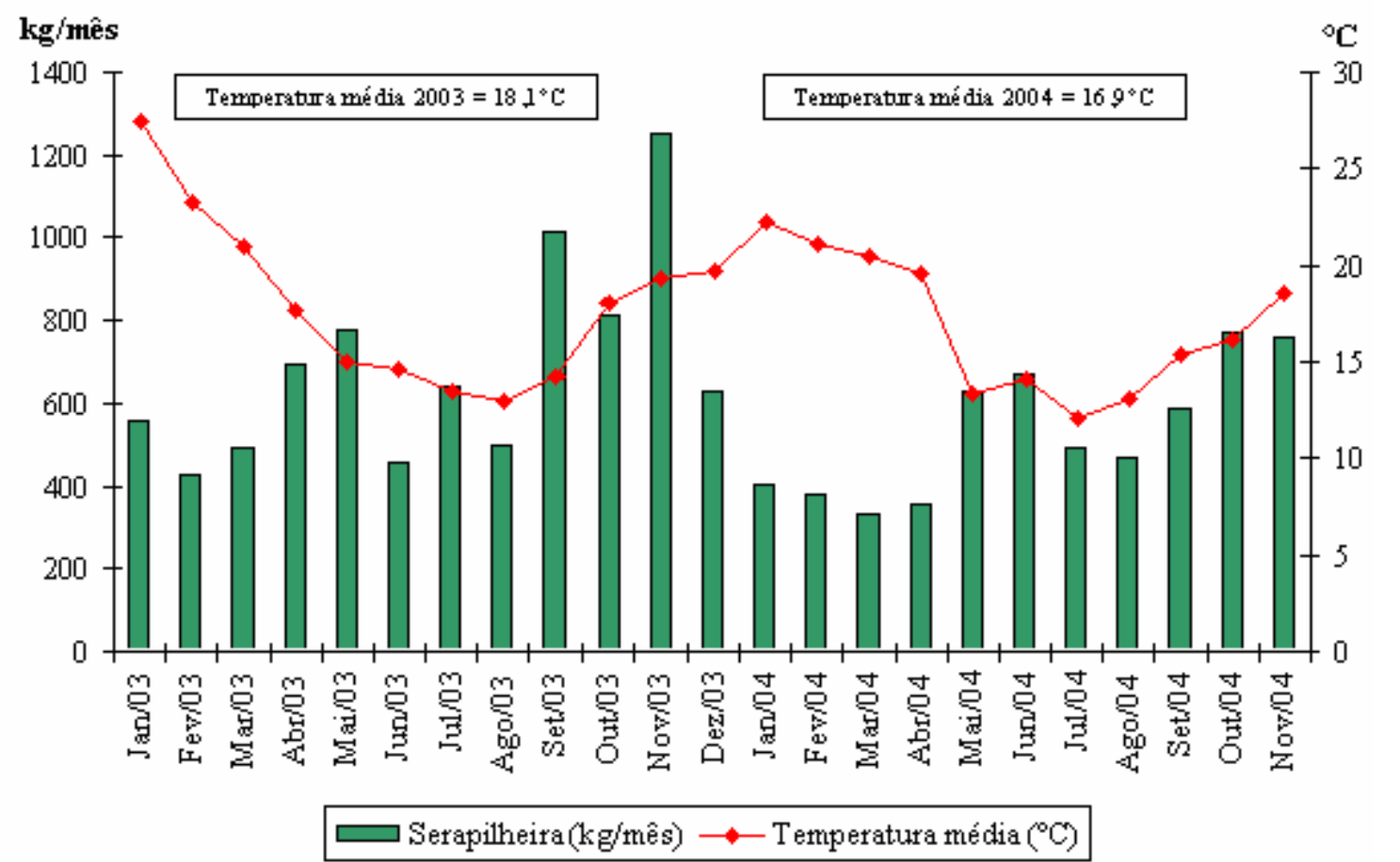

FIGURA 4: Produção média mensal de serapilheira na Floresta Estacional Decidual e a temperatura média mensal, em Itaara, RS, Brasil.

FIGURE 4: Litter monthly average production in Seasonal Deciduous Forest and the average temperature in Itaara, RS, Brazil.

Observa-se, na Figura 4, que há uma pequena tendência, nos períodos de elevada temperatura, de ocorrer uma menor devolução de serapilheira. Observa-se que, no ano de 2003, a temperatura média anual foi de $18,1^{\circ} \mathrm{C}$ e que, no ano de 2004 , foi de $16,9^{\circ} \mathrm{C}$, ou seja, em 2003 , houve maior devolução de serapilheira 
com uma temperatura média anual maior do que em 2004.

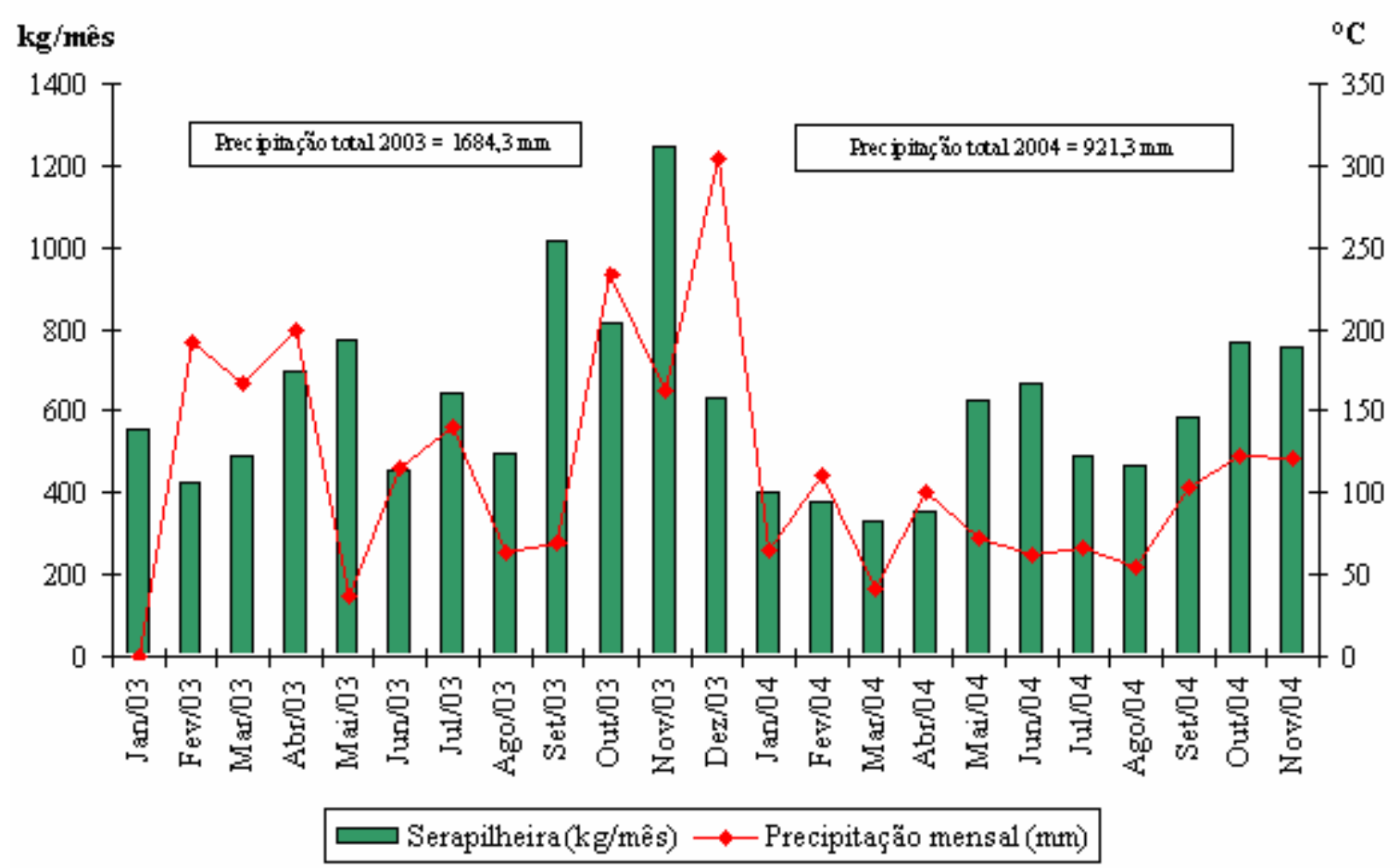

FIGURA 5: Produção média mensal de serapilheira na Floresta Estacional Decidual e a precipitação mensal em Itaara, RS, Brasil.

FIGURE 5: Litter monthly average production in Seasonal Deciduous Forest and the monthly precipitation in Itaara, RS, Brazil.

Quanto à precipitação anual, nota-se, na Figura , que, no ano de 2003, choveu 1684,3 mm, e, no ano de 2004 foi de 921,3 mm, ou seja, no ano de 2004, choveu quase a metade do que em 2003. Como pode-se observar nas , em um ano mais chuvoso e com temperatura média mais elevada, ocorra maior devolução de serapilheira.

Estudos realizados por Cunha (1997), constataram que as maiores produções de serapilheira ocorreram quando as precipitações foram abundantes e a temperatura estava em elevação. Porém, essa afirmação é difícil de ser atribuída a essas variáveis climáticas. Os ventos também são uma fonte importante de derrubada de folhas nas florestas. Uma vez que a maior deposição de serapilheira ocorreu em novembro de 2003, período do ano em que ocorrem às tempestades tropicais, esta pode também estar atribuída a esse fator ambiental.

Estes resultados indicam que somente o uso das variáveis climáticas temperatura média e precipitação mensal pode não ser suficiente para correlacionar a devolução de serapilheira com essas variáveis ambientais, uma vez que não foi verificado correlação significativa. Talvez seja necessário o uso de mais variáveis climáticas, como por exemplo, velocidade de ventos e direção, e a ocorrência de tempestades no local, bem como um período maior do que dois anos de observação.

Outro aspecto importante está relacionado ao local onde são coletadas as informações climáticas. Normalmente, essas informações são coletadas na estação climática mais próxima do local experimental, como é o caso do presente trabalho (INPE de São Martinho da Serra).

O ideal seria a disponibilidade de uma estação no próprio local do experimento e a continuidade da pesquisa num período maior, o que provavelmente poderá trazer informações mais seguras a respeito da correlação com estas variáveis, conforme já foi apontado por Figueiredo Filho et al. (2003) em seus estudos com serapilheira. 


\section{CONCLUSÕES}

Nos dois anos de coleta, houve grande devolução de serapilheira no início do inverno e principalmente na primavera, aumentando nos meses de setembro e novembro, no primeiro ano. No segundo ano, apesar da menor devolução mensal, essa tendência manteve-se mais ou menos constante, indicando um padrão sazonal na floresta onde foi realizado este estudo.

A devolução média anual de serapilheira foi de 7436,0 $\mathrm{kg} \mathrm{ha}^{-1}$, com uma distribuição relativa de 71,7\% de folhas, 16,5\% de galhos finos e 11,8\% de miscelânea.

Não foi verificada uma correlação significativa entre as variáveis climáticas precipitação e temperatura e a devolução de serapilheira.

A serapilheira devolvida representa um grande aporte de material orgânico para o ecossistema.

\section{REFERÊNCIAS BIBLIOGRÁFICAS}

ALBERTI, L. F.; SCHUMACHER, M. V.; BARICHELLO, L. R. et al. Análise de solo e serapilheira em floresta Estacional Decidual, no município de Santa Maria, RS. In: CONGRESSO FLORESTAL ESTADUAL, 8., 2000, Nova Prata. Nova Prata: Prefeitura Municipal, 2000. 1 CD-ROM.

ANDRAE, F.; KRAPFENBAUER, A. Inventário de um reflorestamento de Araucária de 17 anos em Passo Fundo-RS: Inventário da biomassa e nutrientes. In: ANDRAE, F.; KRAPFENBAUER, A. Pesquisas Austríaco-Brasileiras 19731982. Wien: Universität für Bodenkultur,1983. p.16-55.

BARICHELLO, L. R.; SCHUMACHER, M. V.; VOGEL, H. L. M. et al. Quantificação dos nutrientes no solo e serapilheira de diferentes estágios sucessionais em um sistema de agricultura migratória. In: REUNIÃO SULBRASILEIRA DE CIÊNCIA DO SOLO, 3., 2000, Pelotas. Resumos expandidos... Pelotas, 2000. 1 CD-ROM.

BRAY, J. R.; GORHAM, E. Litter production in forests of the world. Advances in Ecological Research, London, v. 2, p. 101-157, 1964.

BRUN, E. J.; SCHUMACHER, M. V.; VACCARO, S. Produção de serapilheira e devolução de nutrientes em três fases sucessionais de uma Floresta Estacional Decidual no município de Santa Tereza (RS). In: SIMPÓSIO DE FERTILIZAÇÃO E NUTRIÇÃO FLORESTAL, 1., 1999, Piracicaba. Anais... Piracicaba: ESALQ, 1999. p.348-364.

BRUN, E. J. Biomassa e nutrientes na floresta Estacional Decidual, em Santa Tereza, RS. 2004. 136f. Dissertação (Mestrado em Engenharia Florestal) - Universidade Federal de Santa Maria, Santa Maria.

CALDEIRA, M. V. W. Determinação de biomassa e nutrientes em uma floresta Ombrófila Mista Montana em General Carneiro, Paraná. 2003. 176f. Tese (Doutorado em Ciências Florestais) - Universidade Federal do Paraná, Curitiba.

CUNHA, G. C. Aspectos da Ciclagem de nutrientes em diferentes fases sucessionais de uma Floresta Estacional do Rio Grande do Sul. 1997. 86f. Dissertação (Mestrado em Engenharia Florestal) - Escola Superior de Agricultura "Luiz de Queiroz", Piracicaba.

FEGER, K. H.; RASPE, S. Ökosystemforschung im chwarzwald: Auswirkungen von atmogenen einträgen und Restabilisierungsmassnahmen auf den Wasser- und Stoffhaushalt von Fichtenwäldern. In: RASPE, FEGER und ZÖTTL (Hrsg). Verbundprojekt ARINUS. Landsberg: Umweltforschung in Baden-Württenberg, 1998. p.1-18.

FIGUEIREDO FILHO, A.; MORAES, G. F.; SCHAAL, L. B. et al. Avaliação estacional da deposição de serapilheira em uma floresta ombrófica mista localizada no sul do estado do Paraná. Ciência Florestal, Santa Maria, v.13, n.1, p.11-18, 2003.

GONÇALVES, J. L. de M.; MELLO, S. L. de M. O sistema radicular das árvores. In: GONÇALVES, J. L. de M.; BENEDETTI, V. Nutrição e fertilização florestal. Piracicaba: IPEF, 2000. p.219-267.

GREFF, L. T. B.; LONGHI, S. J.; BRUN, F. G. K. et al. Estrutura fitossociológica de um fragmento de Floresta Estacional Decidual no município de Itaara, RS. In: SIMPÓSIO DE PÓS-GRADUAÇÃO EM CIÊNCIAS FLORESTAIS, 4., 2006, Piracicaba. Anais... Piracicaba : Esalq, 2006. 1 CD-ROM.

KÖNIG, F. G.; SCHUMACHER, M. V.; BRUN, E. J. et al. Avaliação da sazonalidade da produção de serapilheira numa floresta Estacional Decidual no município de Santa Maria-RS. Revista Árvore, Viçosa, v.26, n.4, p. 429-435, 2002.

MORENO, J. A. Clima do Rio Grande do Sul. Porto Alegre: Secretaria da Agricultura, 1961. 73p.

MOREIRA, F. M. S.; SIQUEIRA, J. O. Microbiologia e bioquímica do solo. Lavras: Ed. UFLA, 2002. 626p. 
POGGIANI, F.; SCHUMACHER, M. V. Ciclagem de nutrientes em Florestas Nativas. In: GONÇALVES, J.L. M.; BENEDETTI, V. (Eds.). Nutrição e fertilização florestal. Piracicaba : IPEF, 2000. p. 287-308.

REIS, M. G. F.; BARROS, N. F. Ciclagem de nutrientes em plantios de eucalipto. In: BARROS, N. F. \& NOVAIS, R. F. (eds.). Relação solo-eucalipto. Viçosa: Ed. Folha de Viçosa, 1990. p.265-302.

REISSMANN, C. B.; WISNIEWSKI, C. Aspectos nutricionais de plantios de Pinus. In: GONÇALVES, J. L.; BENEDETTI, V. (eds.). Nutrição e fertilização florestal. Piracicaba: IPEF, 2000. p.135-166.

SCHUMACHER, M. V.; CALDEIRA, M. V. W.; SPATHELF, P. et al. Quantifizierung der Biomasse und dês Nährstoffgehalts bei der Restdurchforstung eines Araukarienbestandes in Quedas do Iguaçu (Paraná, Brasilien). Forstarchiv n.73, p. 187-194, 2002.

STRECK, E. V.; KÄMPF, N. DALMOLIN, R. S. D. et al. Solos do Rio Grande do Sul. Porto Alegre: EMATER/RS; UFRGS, 2002. 107p.

TOLEDO, L. O.; PEREIRA, M. G.; MENEZES, C. E. G. Produção de serapilheira e transferência de nutrientes em florestas secundárias localizadas na região de Pinheiral, RJ. Ciência Florestal, Santa Maria, v. 12, n. 2, p. 9-16, 2002.

VOGEL, H. L. M.; SCHUMACHER, M. V.; LOPES, V. G. Biomassa e nutrientes na serapilheira de uma floresta Estaconal Decidual. In: CONGRESSO FLORESTAL ESTADUAL DO RIO GRANDE DO SUL, 9., 2003, Nova Prata. Anais... Nova Prata: Prefeitura Municipal, 2003. 1 CD-ROM. 